\title{
Morphological Characterization by SEM, TEM and AFM of Nanoparticles and Functional Nanocomposites based on Natural Rubber Filled with Oxide Nanopowders
}

\author{
Felipe Silva Bellucci ${ }^{1,2, a}$, Leandra Oliveira Salmazo ${ }^{1, b}$, \\ Eduardo Roque Budemberg ${ }^{1, c}$ Ariel Rodrigo Guerrero ${ }^{3, d}$, \\ Ricardo Flavio Aroca ${ }^{3, \mathrm{e}}$, Marcos Augusto de Lima Nobre ${ }^{2, \mathrm{f}}$,
}

\author{
Aldo Eloizo Job ${ }^{1, g}$
}

1) Laboratório de Tecnologia da Borracha, FCT - Faculdade de Ciências e Tecnologia, UNESP _ Univ Estadual Paulista, C.P. 467, CEP 19060-900, Presidente Prudente, SP, Brazil.

2) Laboratório de Compósitos e Cerâmicas Funcionais - LaCCeF, FCT - Faculdade de Ciências e Tecnologia, UNESP - Univ Estadual Paulista, CEP 19060-900, Presidente Prudente, SP, Brazil.

3) Materials and Surface Science Group, University of Windsor, Windsor/ON, N9B3P4, Canada.

a felipe.bellucci@mct.gov.br, ${ }^{b}$ lesalmazo@yahoo.com.br, ${ }^{c}$ guerrero@uwindsor.ca,

d e.budemberg@gmail.com, ${ }^{\mathrm{e}}$ raroca1@cogeco.ca, ${ }^{\mathrm{f}}$ nobremal@fct.unesp.br, ${ }^{\mathrm{g}}$ job@fct.unesp.br

Keywords: Oxide Nanopowders, Natural Rubber, Ferroelectric Nanocomposites, Morphological Characterization.

\begin{abstract}
Nanocomposites were prepared from mixture of different concentrations of ferroelectric nanoparticles in an elastomeric matrix based on the vulcanized natural rubber. The morphological characterization of nanocomposites was carried out using Scanning electron microscopy (SEM), Transmission electron microscopy (TEM) and Atomic force microscopy (AFM). The nanocrystalline ferroelectric oxide is potassium strontium niobate (KSN) with stoichiometry $\mathrm{KSr}_{2} \mathrm{Nb}_{5} \mathrm{O}_{15}$, and was synthesized by the chemical route using a modified polyol method, obtaining particle size and microstrain equal to $20 \mathrm{~nm}$ and 0.32 , respectively. These ferroelectric nanoparticles were added into the natural rubber in concentrations equal to $1,3,5,10,20$ and $50 \mathrm{phr}$ (parts per hundred of rubber) forming ferroelectric nanocomposites (NR/KSN). Using morphological characterization, we identified the maximum value of surface roughness at low concentrations, in particular, sample with $3 \mathrm{phr}$ of nanoparticles and factors such as encapsulation and uniformity in the distribution of nanoparticles into the natural rubber matrix are investigated and discussed.
\end{abstract}

\section{Introduction}

Niobates with tetragonal tungsten bronze TTB structure are potential materials for laser modulation, frequency multiplicity, second harmonic generation, application in pyroelectric detectors and piezoelectric transducers [1]. In addition some materials with TTB structure exhibit a high dielectric constant. These properties have advanced these oxides into ferroelectric materials of great technological interest, in particular for growing areas such as wireless telecommunications devices. Some polycation ferroelectric oxides have also emerged due to the progress of microwave telecommunications involving satellite broadcasting and other related devices. The $\mathrm{KSr}_{2} \mathrm{Nb}_{5} \mathrm{O}_{15}$ compound with a TTB-type structure has been scantily investigated. It is a ferroelectric material with a large pyroelectric coefficient, and excellent piezoelectric and electro-optic properties [1,2]. A clear anomaly in the dielectric constant occurs at the Curie temperature, at around $160^{\circ} \mathrm{C}[1,2]$. $\mathrm{KSr}_{2} \mathrm{Nb}_{5} \mathrm{O}_{15}$ is a unipolar ferroelectric material with a single polar axis along the [001] direction of the TTB crystal structure, the same axis of the niobium backbone. Cation substitution at the $\mathrm{Nb}$ site is an interesting tool to modify the electrical properties of $\mathrm{KSr}_{2} \mathrm{Nb}_{5} \mathrm{O}_{15}$ [1,2]. Materials at the nanometric scale, regardless of their nature whether ceramic, polymer, metal or composite, are different in relation to materials at a higher dimensional scale due to their surface to volume ratio. 
These differentiated properties can be transferred to other materials by the insertion of the nanomaterials in a matrix of a different nature generating a nanocomposite material [3]. For instance, inorganic/polymer nanocomposites are: (1) carbon nanotubes embedded in thermoplastic and elastomeric matrices producing significant mechanical improvements in the nanocomposites [4]; (2) barium strontium titanate in a low loss dielectric matrix that can be applied in microwave devices for wireless telecommunications, including tunable mixers, delay lines and filters [4]; (3) magnetic nanoparticles like nickel-zinc ferrite dispersed in vulcanized natural rubber forming rubber ferrite composites (RFCs) or magnetic polymer nanocomposites (MPNCs) that can be tailored for various potential applications in electrical and electronic industry, information storage devices and microelectromechanical systems (MEMS) [5]; and (4) rubber nanocomposites containing different concentrations of ferroelectric $\left(\mathrm{KSr}_{2} \mathrm{Nb}_{5} \mathrm{O}_{15}\right)$ and paramagnetic $\left(\mathrm{Ni}_{0.5} \mathrm{Zn}_{0.5} \mathrm{Fe}_{2} \mathrm{O}_{4}\right)$ nanoparticles, where it has been shown that increasing the concentration of nanoparticles enhances the mechanical properties and functionalizes the nanocomposites [6]. Therefore, this class of flexible materials, nanocomposites, attracts considerable attention and comprises a significant part in the field of portable devices.

In this paper, $\mathrm{KSr}_{2} \mathrm{Nb}_{5} \mathrm{O}_{15}$ nanopowders that exhibit ferroelectric properties were synthesized by a chemical approach based on the Modified Polyol Method (MPM). Vulcanized natural rubber nanocomposites with different concentrations of niobate nanopowders are prepared. Both morphological characteristic of vulcanized natural rubber and nanocomposites as a function of concentration of ferroelectric nanoparticles and structural properties are discussed.

\section{Materials and Methods}

Preparation of the $\mathrm{KSr}_{2} \mathrm{Nb}_{5} \mathrm{O}_{15}: \mathrm{KSr}_{2} \mathrm{Nb} \mathrm{O}_{15}$ nanometric powders (JCPDS card number 340108) are prepared using a Modified Polyol Method [7,8]; similar syntheses have been reported [9]. Materials: The starting reagents were niobium complex salt $\left(\mathrm{NH}_{4} \mathrm{H}_{2}\left[\mathrm{NbO}\left(\mathrm{C}_{2} \mathrm{O}_{4}\right)_{3}\right] \cdot 3 \mathrm{H}_{2} \mathrm{O}\right.$ with $460.92 \mathrm{~g} / \mathrm{mol})$, potassium carbonate $\left(\mathrm{K}_{2} \mathrm{CO}_{3}\right.$ with $\left.138.21 \mathrm{~g} / \mathrm{mol}\right)$ and strontium carbonate $\left(\mathrm{SrCO}_{3}\right.$ with $147.63 \mathrm{~g} / \mathrm{mol})$. All starting reagents had analytical purity. Synthesis: All metallic oxides of phase were dissolved in nitric acid $\left(\mathrm{HNO}_{3}\right.$ with $\left.63.02 \mathrm{~g} / \mathrm{mol}\right)$ and ethylene glycol $\left(\mathrm{C}_{2} \mathrm{H}_{4}(\mathrm{OH})_{2}\right.$, $62.07 \mathrm{~g} / \mathrm{mol}$ ) and, thus, the system temperature was increased to $180^{\circ} \mathrm{C}$ by a magnetic stirring until the complete dissociation of $\mathrm{NO}_{3}$ group that is characterized by an yellow gas. The pre-calcination was performed at a final temperature of $300^{\circ} \mathrm{C}$, at a heating rate of $10^{\circ} \mathrm{C}$ per minute and flow rate $300 \mathrm{~mL} / \mathrm{min}$ of $\mathrm{N}_{2}$ while the calcination of the $\mathrm{KSN}$ was performed at a final temperature of $450^{\circ} \mathrm{C}$, at a heating rate of $5^{\circ} \mathrm{C} / \mathrm{min}$, flow of $150 \mathrm{~mL} / \mathrm{min}$ of $\mathrm{O}_{2}$ and kept for 2 hours at the final temperature. The cooling process was attained with natural air flow for both steps.

Preparation of the Nanocomposites: Dry natural rubber (cis-1,4-polyisoprene) of the commercial variety $\mathrm{CCB}$ (Crepe Claro Brasileiro - CCB), financed by the DLP Industria $e$ Comércio de Borracha e Artefatos ${ }^{(R)}$ in the city of Poloni/SP was used for the preparation of the nanocomposites. This rubber is obtained in processing plants by the coagulation of latex from the Hevea brasiliensis species, clones RRIM 600. The processing of the natural rubber with specific formulation was carried out in a double-mixer of the Haake brand, model Rheodrive 5000. A mixture of natural rubber with nanoparticles $(1,3,5,10,20$ and $50 \mathrm{phr})$ was made. In the sequence, an activation system consisting of $4 \mathrm{phr}$ of zinc oxide ( $\mathrm{ZnO}$ with $81.38 \mathrm{~g} / \mathrm{mol})$ and $3 \mathrm{phr}$ of stearic acid $\left(\mathrm{CH}_{3}\left(\mathrm{CH}_{2}\right)_{16} \mathrm{COOH}\right.$ with $\left.284.47 \mathrm{~g} / \mathrm{mol}\right)$, which react with each other to form zinc stearate $\left(\mathrm{Zn}\left(\mathrm{C}_{18} \mathrm{H}_{35} \mathrm{O}_{2}\right)_{2}\right)$, was added. The processing parameters were as follows: the temperature of the screw was $40^{\circ} \mathrm{C}$ with a rotation speed of $60 \mathrm{rpm}$ and a mixing time of 5 minutes. $2 \mathrm{phr}$ of sulphur $\left(\mathrm{S}_{8}\right.$ with $\left.240.48 \mathrm{~g} / \mathrm{mol}\right)$ and $1 \mathrm{phr}$ of 2-mercaptobenzothiazol $\left(\mathrm{S}_{2} \mathrm{NC}_{7} \mathrm{H}_{5}\right.$ with $\left.167.24 \mathrm{~g} / \mathrm{mol}\right)$ were added to all samples with the same processing conditions 24 hours after the first mix. The formulations are given in Table 1. After undergoing two mixing processes, the formulations were compressed and molded at $150^{\circ} \mathrm{C}$ with a closing pressure of $2.5 \mathrm{MPa}$ in a pneumatic press for 8.5 minutes, a conventional procedure for natural rubber. In the end of process, it was prepared the follow samples of ferroelectric nanocomposites: NR, NR/KSN-1phr, NR/KSN-3phr, NR/KSN- 
5phr, NR/KSN-10phr, NR/KSN-20phr and NR/KSN-50phr. Similar techniques of processing have been reported $[5,6]$.

Table 1. The vulcanized natural rubber and nanocomposites formulations.

\begin{tabular}{lc}
\hline \multicolumn{1}{c}{ Components } & Quantity $(\mathbf{p h r} *)$ \\
\hline Dry natural rubber & 100 \\
Zinc oxide & 4 \\
Stearic acid & 3 \\
Sulphur & 2 \\
2-Mercaptobenzothiazol & 1 \\
$\mathrm{KSr}_{2} \mathrm{Nb}_{5} \mathrm{O}_{15}$ & $0,1,3,5,10,20$ or 50 \\
\hline phr - Parts per hundred of rubber &
\end{tabular}

\section{Morphological characterization of the Nanopowders and Nanocomposites}

The morphology of the KSN nanoparticles and of the ferroelectric nanocomposites at room temperature was characterized using transmission electron microscopy (TEM), atomic force microscopy (AFM) and scanning electron microscopy (SEM). For the TEM images a JEOL microscope model JEM-1011 HR was used. AFM images were obtained on the contact mode, in a Nanoscope AFM/STM. SEM images were recorded in the JEOL JSM-820 scanning electron microscope model Quanta 200 with field emission gun (FEG).

A description of the characterization procedure of nanopowders and nanocomposites is shown in Figure 1.

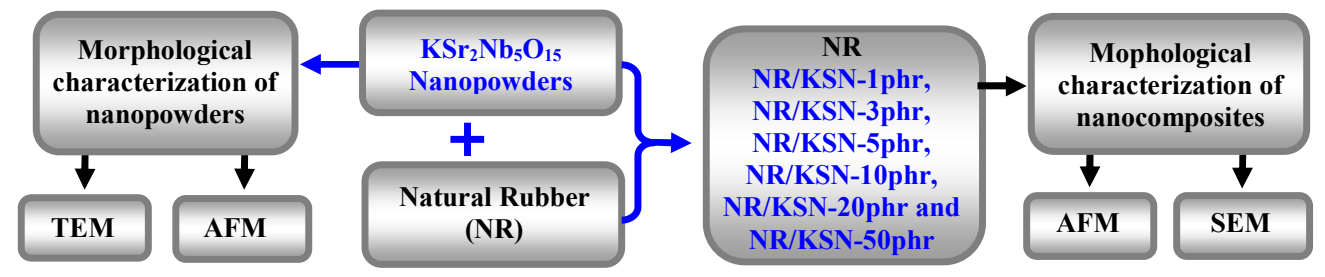

Fig. 1. Flow diagram for the characterization process of the KSN nanopowder and ferroelectric nanocomposites.

\section{Results and Discussions}

At room temperature, the morphological characterization of the KNS nanopowders, calcined at $450^{\circ} \mathrm{C}$, by TEM and AFM are shown in Figure 2. From TEM photograph of the KSN (a), the geometry of primary particles is approximately spherical due to the growth mechanism, in this case nucleation and coalescence to reach a minimum in the surface energy. The average particle size for the $\mathrm{KSN}$ is close to $15 \mathrm{~nm}$ while the size of aggregates is at around $80 \mathrm{~nm}$, with around 100 nanoparticles per cluster. The estimated values are for spherical clusters considered with a closepacking type. According to AFM technique, amplitude image (b) supplies qualitative information about the shape of the nanostructure, while the height image (c) gives significant information on sample surface topography (3D images). In the angle phase deflection images, some details of grain boundary can be observed (small image on the inferior right corner). For KSN phase was identified structures in the nanometric scale, in accordance with Fig. 2 (a). In addition, a particular structure type small aggregate of size equal to $100 \mathrm{~nm}$ is identified being composed of a set of nanoparticles with distribution size between 15 and $30 \mathrm{~nm}$, as we can see in Fig. 2 (b). The formation of small aggregates of nanoparticles is typical for material processing by chemical routes [5]. However, it is important to note that nanoparticles that forming the aggregate are weakly linked by themselves through electrostatic interactions. The average of grain size for Strontium Potassium Niobate is consistent with particle diameters reported elsewhere [1]. 

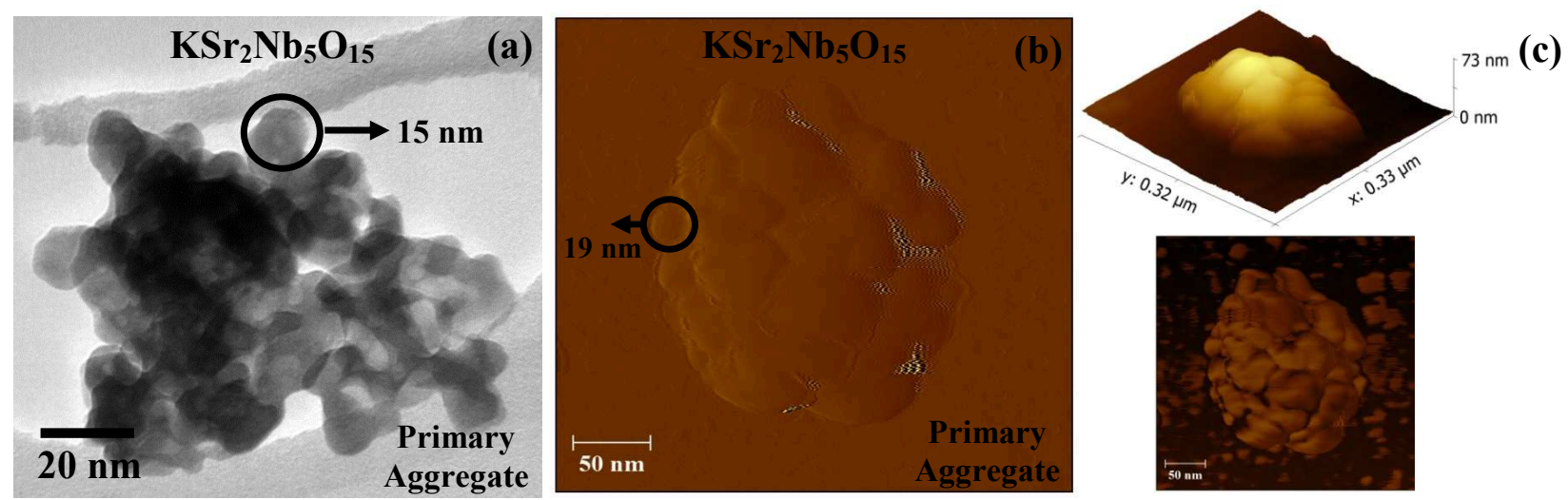

Fig. 2. $\mathrm{KSr}_{2} \mathrm{Nb}_{5} \mathrm{O}_{15}$ nanoparticles calcined at $450^{\circ} \mathrm{C}$ viewing from $\mathrm{TEM}$ photomicrograph (a), amplitude (b), height and angle phase (c) pictures from AFM measurements.

Figure 3 shows a set of images captured directly over the surface of the samples and their respective three-dimensional projection by AFM of vulcanized natural rubber and the ferroelectric nanocomposite formed by the addition of $10 \mathrm{phr}$ of KSN nanopowder in a matrix of vulcanized natural rubber. Table 2 lists values of the parameter surface roughness of the ferroelectric nanocomposites as a function of the nanoparticle concentration. Both sample of vulcanized natural rubber exhibits good surface homogeneity indicating that the system and vulcanization parameters were used in a proper way. Significant differences for surface roughness were identified for the $\mathrm{NR} / \mathrm{KSN}$, when a low amounts of nanometric filler, as example an amount less than $5 \mathrm{phr}$, indicating that phenomena as stress-induced crystallization may be dominant [10]. It seems that differences of surface roughness observed between the ferroelectric nanocomposites can be correlated with: (i) interface filler/matrix phenomena generating changes in the folding of the polymer chains; (ii) the different thermal diffusion coefficient due to the inclusion of a ceramic phase; and (iii) directional anisotropy for the mobility of the polymer chains [10].
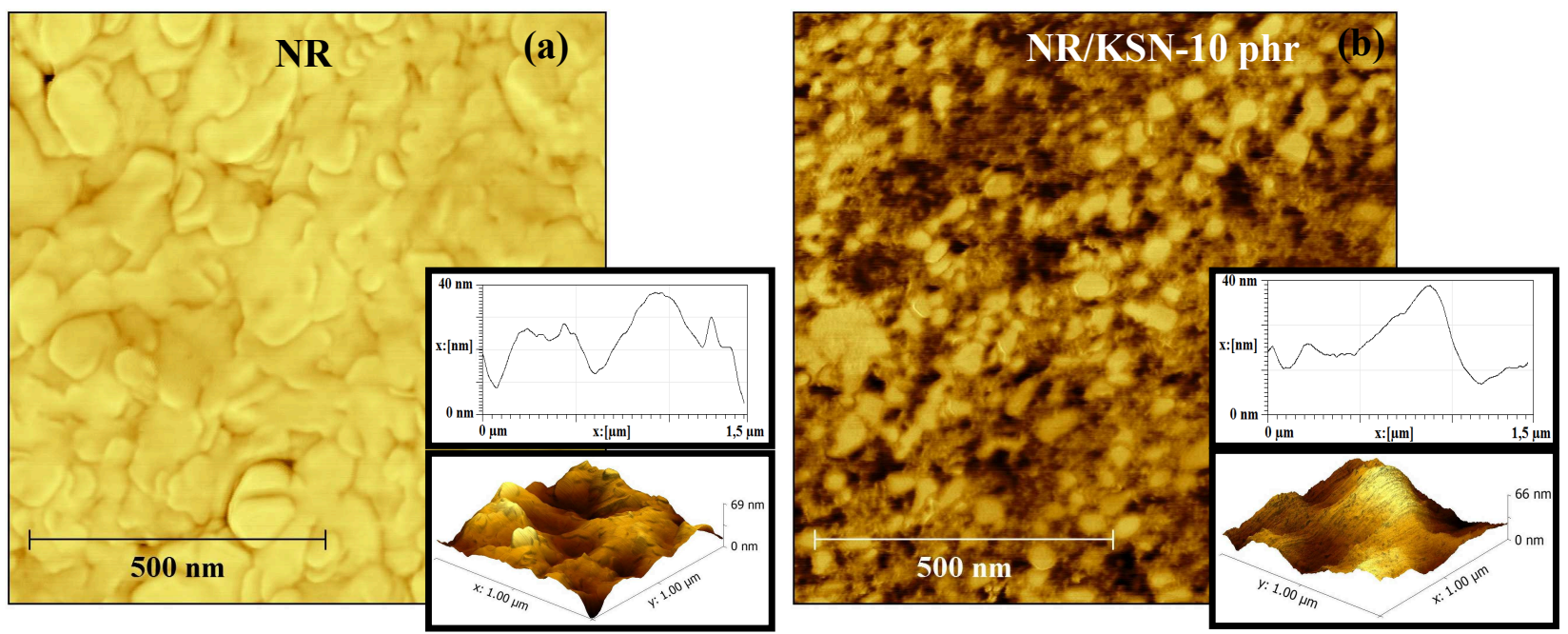

Fig. 3. AFM Micrographs from vulcanized natural rubber NR (a) and ferroelectric nanaocomposite $\mathrm{NR} / \mathrm{KSN}-10 \mathrm{phr}(\mathrm{b})$.

Table 2. List of values for the surface roughness of the ferroelectric nanocomposites as a function of the nanoparticle concentration.

\begin{tabular}{cccccccc}
\hline \multirow{2}{*}{ Sample } & \multicolumn{7}{c}{ Surface Roughness (nm) } \\
\cline { 2 - 8 } & NR & $\mathbf{1} \mathbf{p h r}$ & $\mathbf{3} \mathbf{~ h h r}$ & $\mathbf{5} \mathbf{~ p h r}$ & $\mathbf{1 0} \mathbf{~ p h r}$ & $\mathbf{2 0} \mathbf{p h r}$ & $\mathbf{5 0} \mathbf{~ h h r}$ \\
\hline NR/KSN & 0.45 & 0.68 & 0.83 & 0.70 & 0.55 & 0.50 & 0.58 \\
\hline
\end{tabular}

Figure 4 shows SEM images for vulcanized natural rubber (a) and ferroelectric nanocomposites NR/KSN-10phr. The measurements were performed directly on the fracture 
surface (cross section) of the samples using magnification degree of 5,000 times. According to Fig. 3 , a satisfactory volumetric homogeneity can be observed for all samples investigated indicating that set of parameters assigned to the preparation method, system and vulcanization parameters used were appropriate. The dispersion and size effect of nanometer-sized particles in the polymeric matrix, especially in rubber matrices, have been reported as having a significant impact in the mechanical properties of nanocomposites. Since nanoparticles have a strong tendency to form aggregates, because of their high surface charge and area, homogeneous dispersion of the nanoparticles in the polymer has been considered a difficult process [11]. A good dispersion may be achieved by surface modification of the nanoparticles under appropriate processing parameters. Secondary interactions can occur between certain functional groups attached to the nanoparticle surface and the rubber matrix, wrapping a polymer around the nanoparticle, or by using surfactants. In this sense, a good dispersion degree can be obtained using ultrafine powders with high superficial electric-charge and high surface area. Particles could be identified with nanometric dimensions $(\leq$ $75 \mathrm{~nm})$ and small aggregates $(>75 \mathrm{~nm}$ and $\leq 250 \mathrm{~nm})$ used in the ceramic phase. Sub-micrometric particles $(>250 \mathrm{~nm})$ were also found and are associated mainly with particles of the vulcanization system that are larger than the ceramic nanoparticles synthesized here.
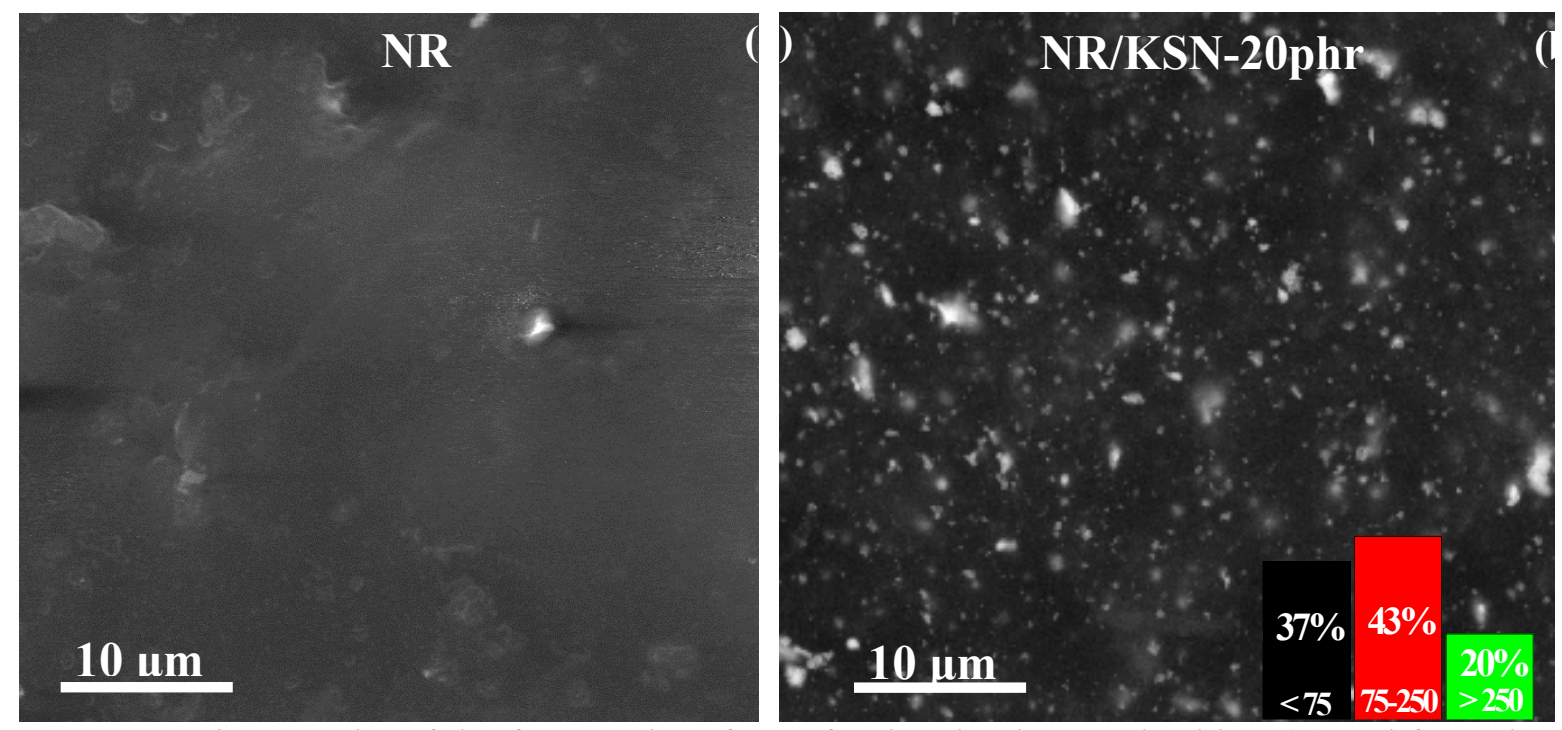

Fig. 4. SEM micrographs of the fractured surface of vulcanized natural rubber (a) and ferroelectric nanocomposites NR/KSN-20phr (b). On the right side, the size distribution of nanoparticles in the polymeric matrix.

\section{Conclusions}

Modified Polyol Method was successfully used to synthesize the ferroelectric oxide Strontium Potassium Niobate with stoichiometry $\mathrm{KSr}_{2} \mathrm{Nb}_{5} \mathrm{O}_{15}(\mathrm{KSN})$, at the nanoscale. Morphological characterizations by TEM and AFM of KSN nanopowders were performed and the particle and aggregate sizes for KSN are approximately 15 and $80 \mathrm{~nm}$. It was identified that the geometry of primary particles is approximately spherical due to the typical growth mechanism of ceramic materials and the surface topography (3D images) of the KSN showed that the nanoparticles in the aggregate are weakly linked by themselves through electrostatic interactions. Nanocomposites containing different concentrations of ferroelectric nanoparticles, 1, 3, 5, 10, 20 and $50 \mathrm{phr}$, were fabricated using a process of hot pressing. Based on AFM and SEM, for all samples investigated, both superficial and volumetric degree of homogeneities indicating that the preparation method is functional. Surface roughness engineered for the NR/KSN depending on the amounts of nanometric filler, which actuate on the parameters stress-induced crystallization, interface filler/matrix, different thermal diffusion coefficient and/or directional anisotropy of the polymer chain. 


\section{Acknowledgements}

The authors are grateful to the Brazilian research agencies (FAPESP, CAPES and CNPq) for financial support, the postgraduate program of Materials Science and Technology POSMAT and National Institutes of Science and Technology - INCTs/MCTI (INEO, Nanobiomed and Nanomed).

\section{References}

[1] S. Lanfredi, G. Palacio, F. S. Bellucci, C. V. Colin and M. A. L. Nobre: J. Phys. D: Appl. Phys. Vol. 45 (2012), p. 435302.

[2] S. Dursun and S. Alkoy: Adv. Mater. Res. Vol. 445 (2012), p. 481.

[3] M.H. Flaifel, S.H Ahmad, M.H. Abdullah and B.A.Al-Asbahi: Cryogenics Vol. 52 (2012), p. 523.

[4] Q. Xu, Y. Yao, Z. Ma and Z. Xia: Sci. Adv. Mater. Vol. 4 (2012), p. 888.

[5] F.S. Bellucci, L.O. Salmazo, E.R. Budemberg, M.R. da Silva, M.A. Rodríguez-Pérez, M.A.L. Nobre and A.E. Job: J. Nanosci. Nanotechnol. Vol. 12 (2012), p. 2691.

[6] F.S. Bellucci, E.R. Budemberg, M.A.L. Nobre, J.A. Saja, R.F. Aroca, M.A. Rodríguez-Pérez and A.E. Job: Sci. Adv. Mater. Vol. 5 (2013), p. 637.

[7] R.J. Joseyphus and B. Jeyadevan: Phys. Chem. Solids Vol. 72 (2011), p. 1212.

[8] S.Lanfredi, I.O. Brito, C. Polini and M.A.L. Nobre:J. Appl. Spectroscopy Vol. 79 (2012), p. 254.

[9] A. Daigle, J. Modest, A. L. Geiler, S. Gillette, Y. Chen,M. Geiler, B. Hu, S. Kim, K. Stopher, C. Vittoria and V. G. Harris: Nanotechnology Vol. 22 (2011), p. 305708.

[10] B. Ozbas, S. Toki, B.S. Hsiao, B. Chu, R.A. Register, I.A. Aksay, R.K. Prud'homme and D.H. Adamson: J. Polym. Sci. Part B: Polym. Phys. Vol. 50 (2012), p. 718.

[11] J. Baller, N. Becker, M Ziehmer, M. Thomassey, B. Zielinski, U. Müller and R. Sanctuary: Polymer Vol. 50 (2009), p. 3211. 